\title{
Immunotherapy with nivolumab for the treatment of soft tissue sarcoma with pulmonary metastasis: A case report
}

\author{
TAYNAH C. PUTY ${ }^{1-3}$, TIAGO G. FRANÇA ${ }^{1,2}$, PAULA B.T. OLIVEIRA ${ }^{4}$, \\ LUÍS EDUARDO W. CARVALHO ${ }^{1,3}$ and NISE H. YAMAGUCHI ${ }^{4}$ \\ ${ }^{1}$ Education and Research Department, Oncológica Brasil - Education and Research, Belém, Pará 66053-000; \\ ${ }^{2}$ Biological and Health Sciences Department, University of Para, Belém, Pará 66087-662; \\ ${ }^{3}$ Epidemiology and Data Analysis Laboratory, Faculty of Medicine of ABC, São Paulo 09060-870; \\ ${ }^{4}$ Education and Research Department, Advances on Medicine Institute, São Paulo 01308-000, Brazil
}

Received November 14, 2018; Accepted June 21, 2019

DOI: $10.3892 / \mathrm{mco} .2020 .2067$

\begin{abstract}
Sarcomas are an unusual group of tumors, accounting for $\sim 1 \%$ of cancer in adults. Immunotherapy has been shown to be a potential therapeutic option for the management of patients with cancer. However, there is still insufficient information on the action of immunotherapy on sarcomas. A 16-year-old male patient, diagnosed in December 2013 with grade III soft-tissue sarcoma in the right arm, was admitted to a private oncology service after relapse following surgical treatment. The patient underwent chemotherapy with ifosfamide plus adriamycin for 4 cycles, associated with adjuvant radiotherapy, followed by a new resection to remove the residual lesion. A year later, imaging tests identified pulmonary micronodules, and a new resection was performed. After immunohistochemical evaluation of biopsy, a large presence of programmed cell death 1 ligand 1 (PD-L1) marker was identified in tumor tissue and immunotherapy with nivolumab was performed. At present, the patient is in immunotherapeutic treatment (42 cycles), presenting an excellent general condition and without any symptoms, and a decrease in neoplastic lung masses. The literature recommends three cycles of anthracycline plus ifosfamide as adjuvant therapy to surgical treatment. Combined surgery plus adjuvant therapy has shown benefits in malignant tumors. Immunotherapy is an important therapeutic option for soft-tissue sarcomas with high programmed cell death protein 1 (PD-1)/PD-L1 expression. Treatment for high grade soft tissue sarcoma (STS) is still limited, due to tumor heterogeneity, and further studies are needed to consolidate the possibility of using immunotherapy to treat these neoplasms. When significant levels of specific biomarkers are present in tumor tissue, immunotherapy may be beneficial as shown by the present case report.
\end{abstract}

Correspondence to: Miss Taynah C. Puty, Education and Research Department, Oncológica Brasil - Education and Research, Visconde de Souza Franco Avenue 570, Belém, Pará 66053-000, Brazil

E-mail: taynah.puty@oncologicadobrasil.com.br

Key words: nivolumab, immunotherapy, immune-checkpoint inhibitors, sarcoma

\section{Introduction}

Sarcomas are tumors originating from the connective tissue matrix, being relatively rare but very invasive (1). Approximately $40 \%$ of the sarcomas occur in the lower extremities, $20 \%$ in the upper extremities (1). They are very rare in adults, accounting for approximately $1 \%$ of the cancers of this population (2) but represent $21 \%$ of malignant soft tissue tumors in the pediatric population (3). In this population, the most common sarcomas are rhabdomyosarcoma and synovial sarcoma (3).

Because of its heterogeneity, it is difficult to define the diagnostic profile of this disease (4). Most sarcomas demonstrate predilection for metastases to the lungs, liver, bones, subcutaneous tissue and lymph nodes (5). However, high-grade sarcomas are associated with a higher incidence of pulmonary metastases, as well as an increased risk of local recurrence and lower survival rates (6). The decision to remove lung metastases through surgery should be made based on the disease-free period after primary surgery, absence of other metastases, number of lesions in each lung, tumor growth, and disease evolution (7).

Advances in target therapies and studies in molecular pathogenesis have led to an increase in the therapeutic arsenal for the treatment of sarcomas. Immunotherapy has been shown to be a potential therapeutic option for the management of cancer patients. Nivolumab is a specific molecular target immunotherapeutic that binds to programmed cell death protein 1 (PD-1), thereby preventing the PD-1 receptor on $\mathrm{T}$ lymphocytes from being activated, what would cause the interruption of the immune attack on cancer cells (8). However, there is still insufficient information on the action of immunotherapy on sarcomas (3). The aim of this paper is to describe a successful treatment to synovial sarcoma using immunotherapy with an anti PD-1 drug. We present the case of a patient diagnosed with soft tissue sarcoma (STS) with pulmonary metastasis treated with nivolumab 19 months ago with good response and without considerable side effects.

\section{Case report}

A 16-year-old male patient presented to the Clinical Oncology Service in December 2013, with a lesion in the right arm, 

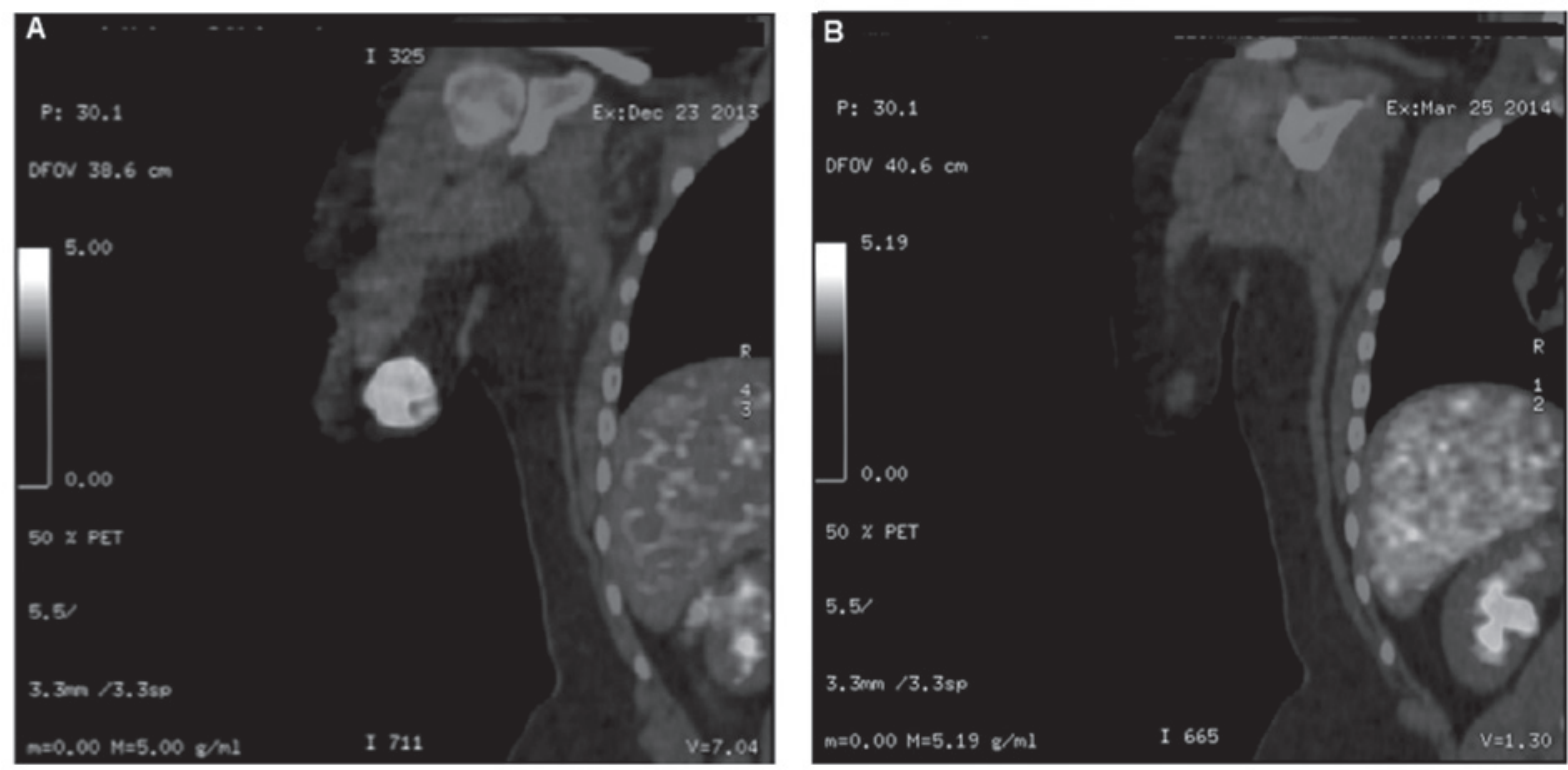

Figure 1. PET-CT. (A) A $3.5 \mathrm{~cm}$ nodule with a standardized uptake value of 8.8 in middle third of right arm. (B) Volumetric and hypercaptation reduction. Significant residual neoplasic activity. PET-CT, positron emission tomography-computed tomography.
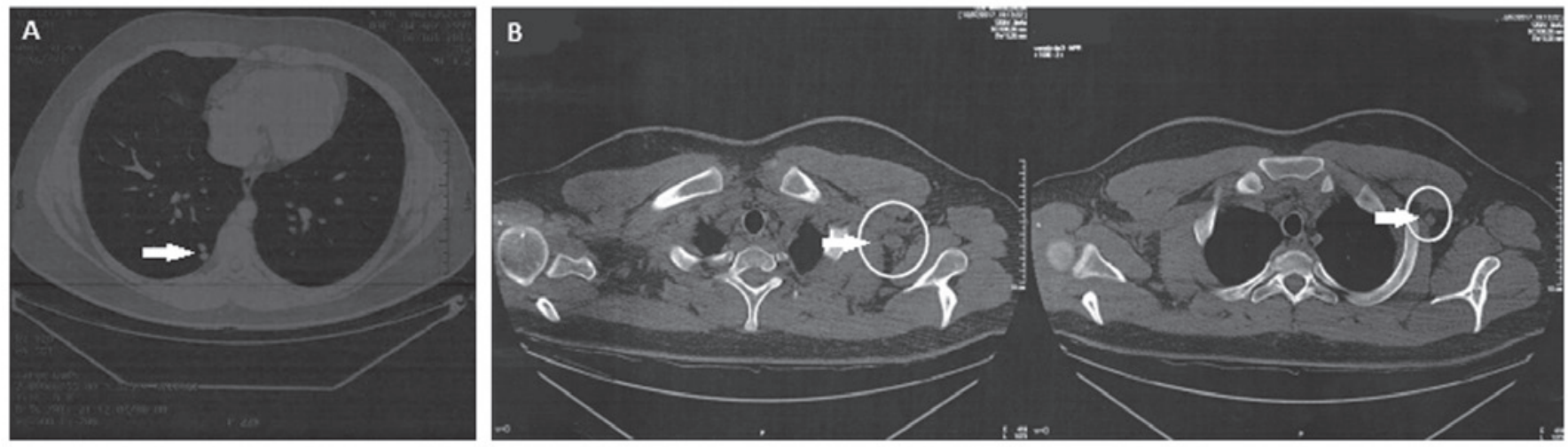

Figure 2. Thorax CT. (A) Peripheral pulmonary micronodules of 0.9 and $0.8 \mathrm{~cm}$. (B) Thorax CT: Expansion of left axillary lymph node. CT, computed tomography.

diagnosed by immunohistochemistry (IHC) as a grade III STS. The patient had already undergone surgery for resection of the tumor in October of 2013, but has presented recurrence in two months. positron emission tomography-computed tomography (PET-CT) revealed a nodule measuring $3.5 \mathrm{~cm}$ (SUV=8.8) in the middle third of the right arm, characterizing recurrence of the lesion (Fig. 1A). Chemotherapy was initiated with ifosfamide $\left(5 \mathrm{mg} / \mathrm{m}^{2}\right)$ and adriamycin $\left(75 \mathrm{mg} / \mathrm{m}^{2}\right)$ every 21 days for 4 cycles.

In April 2014, a new PET-CT showed reduction in the volumetric dimensions of the lesion (from 3.5 to $2.0 \mathrm{~cm}$ ) associated to the hypercaptation degree regression $(\mathrm{SUV}=2,3)$, meaning residual neoplastic activity (Fig. 1B). Therefore, a new surgical treatment was indicated, in which all residual lesions were removed. Subsequently, the patient was referred to IntensityModulated Radiation Therapy (IMRT) radiotherapy, with a dose of $60 \mathrm{~Gy}$ in a tumor bed with margin, in 30 fractions daily of 2 Gy, 5 times a week (Fig. 1A and B).

In July 2015, a computed tomography (CT) scan of the thorax revealed peripheral pulmonary micronodules measuring
0.9 and $0.8 \mathrm{~cm}$ in the right lower lobe (Fig. 2A). The resection of the largest pulmonary nodule has shown undifferentiated malignant neoplasm and the IHQ was compatible with grade III STS.

Pharmacogenomic evaluation, sequencing a panel of 409 genes associated with cancer for the evaluation of mutations was performed in October 2015, out of genomic DNA extracted from the resected tumor and DNA extracted from samples of leucocytes of the blood. Each DNA sample is amplified in 4 reactions. The products of such are sequenced in parallel and then analyzed by software. The test did not present mutations associated with increased sensitivity to treatment with molecular target therapies. However, IHQ showed a large amounts of the Immune Checkpoint PD-1 binding protein (L), which inhibit programmed cell death 1 ligand 1 (PD-L1). Elevated levels of this ligand in tumor tissues, such as those found in our patient, indicate sensitivity of cancer cells to Immune Checkpoints Inhibitors of PD-1 and PD-L1.

Thus, in December 2016, immunotherapy with nivolumab (3 mg/kg in D1 and D15)-preceded by two-days administration of Fexofenadine $120 \mathrm{mg}$ (one tablet twice a day)-was initiated. 
In July 2017, it was performed a new CT scan of the torax, which showed an increase in the left axillary lymph node (Fig. 2B), but the biopsy revealed only reactive lymphoid hyperplasia. Currently, the patient is in the 42 nd cycle of immunotherapy with nivolumab, being asymptomatic and leading a normal life, participating, for example, in aquatic marathons (Fig. 2A and B). Common side effects for nivolumab therapy, such as fatigue, musculoskeletal pain and lymphocitopenia have not been observed throughout follow-up.

\section{Discussion}

Approximately $70 \%$ of all cases of synovial sarcomas occur in the extremities of the body (9). STS management requires a multidisciplinary evaluation, with surgical treatment being the standard modality, associated to auxiliary therapies such as radiotherapy and adjuvant chemotherapy (10). The literature recommends the anthracycline plus ifosfamide program in three cycles, as adjuvant therapy to surgical treatment (11), which corroborates to the medical management adopted in our patient. Patients with sarcomas at the extremities appear to be the major beneficiaries of this therapy (surgery plus adjuvancy) (10). Studies have shown efficacy of this adjuvant chemotherapy in STS, with a reduction in the absolute risk of death by $6 \%$ when compared to the isolated therapy of doxorubicin plus ifosfamide (12-14).

However, many of the patients with high-grade sarcomas still develop metastases (15), which limits the therapeutic possibilities, with the lungs being the main sites (15). The clinical state of our patient followed the same pattern described in the literature $(16,17)$, that is, recurrence of lesions and appearance of metastases, especially in the lungs. Patients with metastatic synovial sarcomas present survival of 7 to 37 months, depending on factors such as lymph node involvement and localization of metastases (18). To date, our patient has been in maintenance of the metastatic framework for 36 months, and 57 months the diagnosis of STS.

Due to the high positivity for the PD-L1 marker in the neoplastic tissue, observed in immunohistochemical analysis, the option for immunotherapy with nivolumab was a viable choice. A cohort study evaluating 28 patients with metastatic sarcomas treated with nivolumab with or without the tyrosine kinase inhibitor (pazopanib) showed evidence of clinical benefits after four cycles (19) of nivolumab. Two other studies were presented at the ASCO 2016 meeting, using pembrolizumab and nivolumab in patients with sarcomas $(20,21)$. However, advances using immunotherapy in sarcomas are still limited, largely due to the heterogeneity of sarcomas (22).

Our results in this case, with the introduction of an immune checkpoint inhibitor, suggest that more studies with immunotherapeutics that target PD-1/PD-L1 overexpression could offer an alternative treatment for patients with STS in order to provide a longer survival with quality of life for these patients. Tumor mutation burden (TMB) variation was not investigated throughout this case, due to financial circumstances of the patient's family. Further studies are also needed to establish definitive therapy for STS that do not respond to chemotherapy.

\section{Acknowledgements}

Not applicable.

\section{Funding}

The present study was supported by Oncológica of Brasil Education and Research.

\section{Availability of data and materials}

All data generated or analyzed during this study are included in this published article.

\section{Authors' contributions}

TGF and TCP reviewed the literature, collected and interpreted the data, wrote the manuscript and conceived the study. PBTO reviewed the literature, wrote the manuscript and conceived the study. LEWC and NHY contributed to the conception and design of the study, and reviewed the methodology. All authors read and approved the final manuscript.

\section{Ethics approval and consent to participate}

Not applicable.

\section{Patient consent for publication}

Formal written consent was obtained for the present case report.

\section{Competing interests}

The authors declare that they have no competing interests.

\section{References}

1. Henshaw RM (ed.): Sarcoma: A Multidisciplinary Approach to Treatment. Springer, Cham, 2017.

2. Somaiah $\mathrm{N}$ and von Mehren M: New drugs and combinations for the treatment of soft-tissue sarcoma: A review. Cancer Manag Res 4: 397-411, 2012.

3. Uehara T, Fujiwara T, Takeda K, Kunisada T, Ozaki T and Udono H: Immunotherapy for bone and soft tissue sarcomas. Biomed Res Int 2015: 820813, 2015.

4. Demicco EG, Maki RG, Lev DC and Lazar AJ: New therapeutic targets in soft tissue sarcoma. Adv Anat Pathol 19: 170-180, 2012.

5. Amankwah EK, Conley AP and Reed DR: Epidemiology and therapies for metastatic sarcoma. Clin Epidemiol 5: 147-162, 2013.

6. Welter S, Grabellus F, Bauer S, Schuler M, Eberhardt W, Tötsch M and Stamatis G: Growth patterns of lung metastases from sarcoma: Prognostic and surgical implications from histology. Interact Cardiovasc Thorac Surg 15: 612-617, 2012.

7. ESMO/European Sarcoma Network Working Group: Soft tissue and visceral sarcomas: Esmo clinical practice guidelines for diagnosis, treatment and follow-up. Ann Oncol 25(Suppl 3): iii102-iii112, 2014.

8. Sharma P, Retz M, Siefker-Radtke A, Baron A, Necchi A, Bedke J, Plimack ER, Vaena D, Grimm MO, Bracarda S, et al: Nivolumab in metastatic urothelial carcinoma after platinum therapy (CheckMate 275): A multicentre, single-arm, phase 2 trial. Lancet Oncol 18: 312-322, 2017.

9. Nielsen TO, Poulin NM and Ladanyi M: Synovial sarcoma: Recent discoveries as a roadmap to new avenues for therapy. Cancer Discov 5: 124-134, 2015. 
10. Brunello A, Rizzato MD, Rastrelli M, Roma A, Maruzzo M, Basso U, Fiduccia P, Buzzaccarini MS, Scarzello G, Rossi CR and Zagonel V: Adjuvant chemotherapy for soft tissue sarcomas: A 10-year mono-institutional experience. J Cancer Res Clin Oncol 142: 679-685, 2016.

11. Guest JF, Panca M, Sladkevicius E, Gough N and Linch M: Cost effectiveness of first-line treatment with doxorubicin/ifosfamide compared to trabectedin monotherapy in the management of advanced soft tissue sarcoma in Italy, Spain, and Sweden. Sarcoma 2013: 725305, 2013.

12. Pervaiz N, Colterjohn N, Farrokhyar F, Tozer R, Figueredo A and Ghert M: A systematic meta-analysis of randomized controlled trials of adjuvant chemotherapy for localized resectable soft-tissue sarcoma. Cancer 113: 573-581, 2008.

13. Casali PG: Adjuvant chemotherapy for soft tissue sarcoma. Am Soc Clin Oncol Educ Book: e629-e633, 2015.

14. Pasquali S and Gronchi A: Neoadjuvant chemotherapy in soft tissue sarcomas: Latest evidence and clinical implications. Ther Adv Med Oncol 9: 415-429, 2017.

15. Zagars GK, Ballo MT, Pisters PW, Pollock RE, Patel SR, Benjamin RS and Evans HL: Prognostic factors for patients with localized soft-tissue sarcoma treated with conservation surgery and radiation therapy An analysis of 1225 patients. Cancer 97: 2530-2543, 2003.

16. Vlenterie M, Litière S, Rizzo E, Marréaud S, Judson I, Gelderblom H, Le Cesne A, Wardelmann E, Messiou C, Gronchi A and van der Graaf WT: Outcome of chemotherapy in advanced synovial sarcoma patients: Review of 15 clinical trials from the European organisation for research and treatment of cancer soft tissue and bone sarcoma group; setting a new landmark for studies in this entity. Eur J Cancer 58: 62-72, 2016.
17. Spurrell E, Fisher C, Thomas JM and Judson IR: Prognostic factors in advanced synovial sarcoma: An analysis of 104 patients treated at the Royal Marsden Hospital. Ann Oncol 16: 437-444, 2005.

18. Salah S, Yaser S, Salem A, Al Mousa A, Abu Sheikha A and Sultan I: Factors influencing survival in metastatic synovial sarcoma: Importance of patterns of metastases and the first-line chemotherapy regimen. Med Oncol 30: 639, 2013.

19. Paoluzzi L, Cacavio A, Ghesani M, Karambelkar A, Rapkiewicz A, Weber J and Rosen G: Response to anti-PD1 therapy with nivolumab in metastatic sarcomas. Clin Sarcoma Res 6: 24, 2016.

20. Tawbi HAH, Burgess MA, Crowley J, Van Tine BA, Hu J, Schuetze S, D'Angelo SP, Attia S, Priebat DA, Okuno SH, et al: Safety and efficacy of PD-1 blockade using pembrolizumab in patients with advanced soft tissue (STS) and bone sarcomas (BS): Results of SARC028-A multicenter phase II study. J Clin Oncol 34: 11006, 2016.

21. George S, Barysauskas CM, Solomon S, Tahlil K, Malley R, Hohos M, Polson K, Loucks M, Wagner AJ, Merriam P, et al: Phase 2 study of nivolumab in metastatic leiomyosarcoma of the uterus. J Clin Oncol 34: 11007, 2016.

22. Bleloch JS, Ballim RD, Kimani S, Parkes J, Panieri E, Willmer T and Prince S: Managing sarcoma: Where have we come from and where are we going? Ther Adv Med Oncol 9: 637-659, 2017. 